\title{
Features of foreign language education
}

\author{
Najmiddinova Mekhrigul Najmiddin Kizi, Ikromov Qamariddin Ilgorbekovich
}

\author{
Master student 1 course, Navoi state pedagogical institute, foreign language faculty
}

\author{
najmiddinovamehrigul@gmail.com
}

\begin{abstract}
This article discusses current issues of learning foreign languages. It also proposes ways to use advanced technologies in the study of foreign languages.
\end{abstract}

Keywords: Learning foreign languages, pedagogical technologies, and practical classes.

\section{INTRODUCTION}

As you know, the practical exercise in the language means the ability to develop speaking skills and skills in the same language. Skills are taught in vocabulary, grammar, pronunciation and ability to listen, speak, read, write.

Auxiliary translation of translation can be considered as mastering the knowledge of a foreign language, which means that this is a special area for those who are in translation departments (faculties).

In other words, speaking, listening, reading and writing in a foreign language require special exercises. In particular, the exercises for the study of words, sentences and texts, such as language and speech units, are justified by the methodology.

It helps to improve the language, communication and socio-cultural skills of communication and communication in a professional context. Special attention is paid to the issues of speaking, speaking, reading and writing, and the relevant skills and abilities are improved. The study of foreign languages according to the curriculum in foreign sciences, the formation of comprehensive vocabulary and vocabulary skills such as general, military, technical and military texts (for example, military technology, agriculture), the development of oral and interpersonal skills is envisaged.

The purpose of teaching a non-native language is to develop the skills to use the learned language as a tool for exchanging ideas, increasing students' awareness and improving their professional skills and abilities.

Language skills of students is a combination of knowledge, skills and competencies accumulated in three languages, the volume, scope and relationship of the subject are necessary conditions for taking into account the experience of the methodology of the language. Learning language experience means that knowledge and skills acquired in Uzbek, Russian and foreign languages (English, Spanish, German or French) are negative (intervening) or positive (transference / acceleration), for example, when learning the word "artikl »In a foreign language it does not exist in the Uzbek language, it forms the concept of a grammatical category of art. As a result, the student / student language experience is now "foreign" with a foreign language [1].

In the process of working with foreign languages, language skills of students are formed mainly in their native language, and in two or more languages, the language of their students increases. As a result, verbal, linguistic and linguistic content is developed in memory and thinking. Different languages and methods are used to express ideas. That is why the problem of differentiation between internal and interlanguage negative (intervention) or positive impact (movement / relief) in the learning process arises in the same language.

The following methods are used to learn new words when working with text in a foreign language:

- write all the new words, the best of them on the cards; each word is written on one card (the German side is the reverse side in the Uzbek language);

- Cards should include as many words and related content as possible: examples, pictures, grammatical information, phonetic notes or even help abroad; 
- Always look at the cards one by one, you will have to remember again that the deleted cards are not yet mastered; even the word word must be repeated;

- Splitting cards into different groups, semantic learning in the form of paired words (for example, synonyms, antonyms), filling in additional information, etc. [3: 9]

L.S. Vigotsky, who speaks the language in two ways, emphasizes: in higher education, the language is learned "from the top down", after consciously using language units and the rules for their use, they are automated in speech and freely used in various communication situations (unconscious). When studying a foreign language as a subject of general education, it is studied "from the bottom up".

Regardless of whether one or more languages are available, the student (in any case) has a certain language experience. Language learning is interpreted as speech, linguistic and linguistic content. The content of the conversation includes the ability to communicate, for example, the transfer of information and the perception of others, the use of linguistic phenomena to receive and transmit information on the linguistic side and, finally, the linguistic aspect of linguistic phenomena. Every three sections constitute a whole "knowledge of the language" [1].

Spoken subjects should be limited to the high school environment (for example, "Environment", "Country", and "Language Learned in the Country"), and university students should be able to communicate in their field outside of these topics. At the University of Foreign Languages, speech subjects are not limited because students learn to communicate freely even in oral / written translations [1: 357].

\section{CONCLUSION}

There are some comments that reading the text in a non-native university is two levels: 1) the level of understanding of the language; 2) The level of understanding of the content. The first level is the interconnectedness of language units. At the second level, the recipient can perceive speech, that is, read or listen. The first line will be a brief overview of the content of the text. The second will be able to extract the information received [6].

The choice of speech objects in the practice of a foreign language occupies a special place. For example, when choosing speech objects, it is based on specific teaching methods: (1) topics should be used to formulate speech skills; (2) availability of teaching and learning opportunities; (3) The choice of topics is focused on mutual and (re) productive features of learning. Consequently, separate topics are used for speaking and reading.

Getting a variety of reproductive (conversational, written) and reciprocal speech actions in a foreign language requires the use of a different methodology. He plays an important role in the practical study of foreign languages.

\section{REFERENCES}

1. Zhalolov Yu.J. Methods of teaching foreign languages: A textbook for students of faculties of foreign languages (faculties). - Tashkent: Teacher, 2012. - $432 \mathrm{p}$.

2. The concept of unprecedented access to the newspaper // The newspaper "Teacher of Uzbekistan". -1993. July 28 - August 3. - pp. 2-3.

3. Why do you need multiline? Warum Mehrsprachigkeit? -T., 2017.

4. Mustafayeva Kh.T. Lingvhoto-photodynamic features of teaching English grammar to students of social and humanitarian faculties: ped. the science. title. ... dis. - Samarkand, 2003. - 139 p.

5. Yerkayev E.T. Linguodidactic classification of translation exercises used in future education for teachers of foreign languages: ped. the science. title. ... dis. books. Tashkent, 2008. - 23 p.

6. Sharapova S.I. Methodology of teaching students of a non-linguistic university of reading professional texts with sometimes-various forms of secondary utterances (German). Author's abstract Nizin ... Cand. PED. The scien 